\title{
Carbon nanotubes as solid-phase extraction sorbents for the extraction of carbamate insecticides from environmental waters
}

\author{
L. Latrous El Atrache ${ }^{1,2} \cdot$ M. Hachani ${ }^{1}$ B. B. Kefi ${ }^{3}$
}

Received: 12 January 2015/Revised: 1 May 2015 / Accepted: 7 July 2015/Published online: 28 July 2015

(C) Islamic Azad University (IAU) 2015

\begin{abstract}
Multiwalled carbon nanotubes have been used for the first time as solid-phase extraction sorbents for the extraction of five $N$-methylcarbamate insecticides (i.e., carbaryl, carbofuran, aminocarb, methiocarb, and zectran) from different surface water samples. An effective and sensitive method was developed by combining solid-phase extraction and liquid chromatography-electrospray ionization-mass spectrometry detection. Important parameters influencing the extraction efficiency such as kind and volume of elute, volume of water samples, and adsorbent mass were optimized. Under the optimized extraction conditions, good linearity was obtained for all carbamates $\left(r^{2}>0.995\right)$ over the range of $0.005-1 \mathrm{mg} \mathrm{L}^{-1}$. The limits of detection and quantification were $0.01-0.05$ and $0.08-0.2 \mu \mathrm{g} \mathrm{L}^{-1}$, respectively. The optimized solid-phase extraction procedure was compared in terms of adsorption capacity to $\mathrm{C} 18$ silica and activated carbon. The adsorption capacity of multiwalled carbon nanotubes was larger than activated carbon. The proposed method was successfully applied to the analysis of tap and surface waters, and mean recoveries for five carbamates were from 92.2 to $103.9 \%$ with relative standard deviation between 0.4 and $7.0 \%$.
\end{abstract}

L. Latrous El Atrache

latifa.latrous@ipeiem.rnu.tn

1 Laboratoire de Chimie Analytique et Electrochimie, Faculté des Sciences de Tunis, Université de Tunis El Manar, Campus Universitaire 2092, Tunis, Tunisia

2 Institut Préparatoire aux Etudes d'Ingénieurs d'El Manar, Université de Tunis El Manar, El Manar II 2092, B.P.244, Tunis, Tunisia

3 Institut National de Recherche et d'Analyse Physicochimique, pôle technologique sidi-thabet 2020, Tunis, Tunisia
Keywords Carbamate pesticides - Multiwalled carbon nanotubes · Solid-phase extraction $\cdot$ Water $\cdot$ Liquid chromatography-mass spectrometry

\section{Introduction}

Carbamate insecticides are among the most commonly employed pesticides worldwide. Although carbamates as a whole are not the most toxic pollutants, they are very toxic when absorbed by humans because of acetylcholinesterase deactivation (Worek et al. 2008; Tsoukali and Tsoungas 1996). Carbamates are included in the list of the United States Environmental Protection Agency (EPA; USEPA. 1992) for prioritizing control of their application. Some compounds of this group were carbaryl, carbofuran, and aldicarb, and among these, aldicarb is highlighted as the principal target on the list of the controlled pesticides by the EPA due to its elevated toxicity (USEPA 1992). Their use on potato, citrus, coffee, and other crops is a common practice that can result in the contamination of both surface and groundwaters. According to the European Union (EU) directive on water quality (98/83/CE) (EU Council 1998), the maximum admissible concentration for pesticides is $0.1 \mu \mathrm{g} \mathrm{L}^{-1}$ for each individual substance and $0.5 \mu \mathrm{g} \mathrm{L}^{-1}$ for the sum of pesticides in drinking water. Therefore, there is a considerable interest in the development of highly sensitive, selective, rapid, and cost-effective analytical methods or devices for monitoring carbamates. Because the carbamate concentration levels are very low in water samples, sensitive analytical techniques are required to obtain low detection limits. Enrichment separation approaches including solvent extraction, solid-phase extraction (SPE), and solid-phase microextraction (SPME) have been commonly used to improve the instrumental 
limits of detection (Sanusi et al. 2004; Krutz et al. 2003; Albero et al. 2005; Lancas 2004; Picó et al. 2007; El Atrache and Sabbah 2003; Soriano et al. 2001; USEPA Method 531 1985). In this sense, SPE procedures have a very important role in preconcentration studies due to their simplicity, high enrichment factors, environmental friendliness, etc.

In SPE, the choice of an appropriate stationary phase is a critical factor to achieve full recovery and high enrichment efficiency. Carbon nanotubes (CNTs) are novel and interesting carbon nanomaterials first found in 1991 by Iijima that have originated a wide variety of applications in analytical sciences (Iijiama and Ichihashi 1993). Carbon nanomaterials include fullerenes, single-walled CNTs (SWCNTs), and multiwalled CNTs (MWCNTs). They have attracted great attention due to their unique tubular structures and large length-to-diameter ratio, and their chemical, electronic, and mechanical properties. The exceptional properties that these materials possess open new environmental field. These properties offer opportunities for a wide range of applications for the detection and remediation of different contaminants and water treatment. The use of CNTs as sorbent for metal species in SPE has been described (Salam 2013). Physical and chemical strategies for functionalization of CNTs have been discussed (Saleh et al. 2011; Gupta et al. 2011a; Crecente et al. 2014; Jun-ping et al. 2007; Latorre et al. 2012). Oxidation was performed by refluxing the MWCNTs in nitric acid or mixtures of sulfuric acid and nitric acid at different temperatures (Saleh 2011). Carbon nanotubes nano-iron oxide composites were prepared and characterized for the removal of chromium (Gupta et al. 2011b). Dye adsorption capability of CNTs and CNT-based composites from aqueous solutions has been compiled (Saleh and Gupta 2012; Gupta et al. 2013). The use of wastetire-derived carbon to remove various types of pollutants from aqueous media was highlighted (Saleh and Gupta 2014). A detailed description of the preparation and treatment method of porous carbon, CNTs, and fullerene along with relevant applications and regeneration is also included (Gupta and saleh 2013). It is also shown that MWCNTs possess remarkable potential for SPE of trace phtalates (Zhoua et al. 2006a). Chen et al. (2011) reported the removal of two herbicides (diuron and dichlobenil) from contaminated water using MWCNTs. The adsorption of diuron onto as-prepared and oxidized MWCNTs was studied by Deng et al. (2012), with the oxidation treatment increasing the surface area and pore volume and resulting in an increased adsorption. SWCNTs have been demonstrated to have a higher adsorption capacity for 4-chloro-2-methylphenoxyacetic acid (MCPA), a phenoxy acid herbicide, than three kinds of MWCNTs (with average outer diameters of 15, 30, and $50 \mathrm{~nm})$ and several nanoscale metal oxides $\left(\mathrm{Al}_{2} \mathrm{O}_{3}\right.$, $\mathrm{TiO}_{2}$, and $\mathrm{ZnO}$ ); the adsorption kinetics usually followed pseudo-second-order kinetics, with the adsorption process being spontaneous and exothermic (Zhoua et al. 2006b). Simultaneous determination of atrazine and simazine in water samples using CNT-packed cartridge for SPE extraction prior to HPLC analysis was investigated (De Martino et al. 2012). The adsorption of atrazine from aqueous solution by granular activated carbon (AC) and CNTs also occurred via the same kinetic and thermodynamic processes (Rambabu et al. 2012). CNT-reinforced hollow fiber SPME coupled with high-performance liquid chromatography have been applied in the determination of some carbamates from fruit samples (Zhao et al. 2011; Song and Shi 2013). Electrophoresis with UV detection was combined with SPE using MWCNTs as stationary phase to determine a group of seven pesticides in mineral water (Ramos et al. 2008) and salicylic acid from river water (Caballero-Díaz and Valcárcel 2014). Overall, CNT adsorption technology has the potential to be used for the removal of pollutants. Unlike many adsorbents, CNTs possess fibrous shape with high aspect ratio, large accessible external surface area, and well-developed mesopores, all contribute to the superior removal capacities. Despite their utility as SPE sorbents, CNTs have only been used in few occasions for the extraction of pesticides from water samples. Moreover, few comparative studies were reported in the literature among various sorbents (D'Archivio et al. 2007; Zhou et al. 2006; El-Sheikh et al. 2008).

In this work, an efficient extraction procedure was proposed, in which CNTs were used as adsorbents for SPE, in combination with liquid chromatography. Electrospray ionization-mass spectrometry detection (ESIMS) was reported for the analysis of five carbamate insecticides in water samples. The potential factors affecting the SPE of the analytes were optimized and discussed in detail. A comparison between AC with MWCNTs and C-18 silica for selected insecticides from environmental waters prior to their simultaneous analysis by LC-ESI-MS was investigated. To the best of our knowledge, the application of MWCNTs as SPE sorbent for preconcentration of aminocarb, carbofuran, carbaryl, methiocarb, and zectran has not been reported in the literature. Moreover, a comparison report between MWCNTs and traditional adsorbents for these model compounds was not found. This research has been carried out in the chemistry department, Faculty of Sciences, Tunis- El Manar University (Tunis, Tunisia), in September 2014. 


\section{Materials and methods}

\section{Chemicals and materials}

The HPLC-grade water was obtained by purification of demineralized water in a Milli-Q system (Millipore, Elix). Methanol and acetonitrile, LC grade, were purchased from LAB SCAN (Ireland). The certified pure products were purchased from Supelco. The purity of all standards was a minimum of $99 \%$. Standard stock solutions of $1000 \mu \mathrm{g} \mathrm{mL}^{-1}$ were prepared by weighing and dissolving $20 \mathrm{mg}$ of each compound in $20 \mathrm{~mL}$ of methanol. These solutions were stored at $4{ }^{\circ} \mathrm{C}$. The analyzed pesticide carbamates were aminocarb, carbofuran, carbaryl, methiocarb, and zectran. The chemical structures of all studied compounds are shown in Fig. 1.

Standard mixtures were prepared by appropriate dilution of a mixed stock solution with methanol ranging from 0.005 to $1 \mathrm{mg} \mathrm{L}^{-1}$.

MWCNTs were purchased from Sigma-Aldrich (France). MWCNTs were of 5-9 $\mu \mathrm{m}$ length and 110-170 nm external diameter. AC was purchased from Sigma (untreated granular activated charcoal, 20-60 mesh, product number C3014). Silica-based sorbents with octadecyl functional group Bond Elut Jr. C-18 were acquired from Varian.

\section{Apparatus}

The LC-MS analyses were performed using a PerkinElmer LC system consisting of a 200 quaternary pump; a Rehodyne injection valve (model 7125); and PESciex API 2000 triple quadrupole mass spectrometer equipped with electrospray ionization source.
The HPLC column was Xterra, $250 \times 4.6 \mathrm{~mm}$ i.d., $5 \mu \mathrm{m}$ particulate size. The LC-MS system was connected to analyst station for recording chromatograms. The mobile phase consisted of acetonitrile-water (40-60, v/v). The flow rate of the mobile phase was $1 \mathrm{~mL} \mathrm{~min}^{-1}$. The column effluent was split, allowing only $100 \mu \mathrm{L}$ to enter the mass spectrometer.

\section{Mass spectrometric analysis}

The electrospray ionization-mass spectrometry (ESI-MS) interface was operated in positive mode under the conditions of $325^{\circ} \mathrm{C}$ gas temperature, 30 psi drying gas pressure, 35 psi nebulizer gas pressure, 70 psi additional gas pressure, and $5000 \mathrm{~V}$ of capillary voltage. Full-scan LC-MS chromatograms were obtained by scanning from $\mathrm{m} / \mathrm{z}, 50$ to $400 \mathrm{amu}$. Time-scheduled selected ion monitoring (SIM) of the most abundant ion of each compound was used for quantification. All MS-MS experiments were performed using $\mathrm{N}_{2}$ as the collision gas at a collision cell pressure of $2 \mathrm{~m}$ Torr and with collision energy ranging between 5 and $20 \mathrm{eV}$. Mass analysis was performed in MS-MS product ion mode with the first quadrupole locked on the $\mathrm{m} / \mathrm{z}$ value corresponding to the molecule ion of the target compound, with the second quadrupole known as the collision cell either locked on a characteristic product ion $\mathrm{m} / \mathrm{z}$ or scanning from $\mathrm{m} / \mathrm{z} 50$ to ca. 50 amu above the molecular mass of the target compound (product ion scan) and the third quadrupole that filters the product ions and allows ions of certain mass-to-charge ratio to pass through the detector.

\section{MWCNT cartridge preparation and SPE procedure}

MWCNT-packed cartridge was prepared by placing $0.1 \mathrm{~g}$ of MWCNTs in an empty polypropylene SPE cartridge (3-mL

Fig. 1 Structures of studied carbamate insecticides<smiles>CNC(=O)Oc1cc(C)c(N(C)C)c(C)c1</smiles><smiles>CNC(=O)Oc1cc(C)c(SC)c(C)c1</smiles>

Methiocarb<smiles>CNC(=O)Oc1ccc(N(C)C)c(C)c1</smiles>

Aminocarb 
cartridge from Varian). Polypropylene upper and lower frits (porosity $20 \mu \mathrm{m}$, Varian) were retained at each end of the cartridge to hold the CNTs packing in place. MWCNTs were treated with hydrochloric acid $(\mathrm{HCl} 2 \mathrm{M})$ to remove metal catalyst. Before use, they were dried at $80{ }^{\circ} \mathrm{C}$ for $2 \mathrm{~h}$. The cartridge packed with MWCNTs was first conditioned with $5 \mathrm{~mL}$ of methanol and then with $5 \mathrm{~mL}$ of Milli-Q water. The water sample spiked with five pesticides was passed through the cartridge at an appropriate flow rate. After loading the sample solution, the cartridge was washed with $10 \mathrm{~mL}$ purified water to remove co-adsorbed matrix materials. Subsequently, the five analytes retained on the SPE cartridge were eluted with an optimal volume of a certain eluent, and the resulting elution was blown to dryness with a gentle $\mathrm{N}_{2}$ flow at $40^{\circ} \mathrm{C}$. Finally, the extract was redissolved in $1 \mathrm{~mL}$ methanol and then analyzed by LC-MS.

\section{Water sample}

Samples of tap and surface waters from different sampling sites (Medjerda river, Mellègue river, Siliana river, and Sidi Salem dam) all over Tunisia were collected for pesticide residue analysis. River water samples were collected in brown glass bottles and stored at $4{ }^{\circ} \mathrm{C}$ before analysis. Before being used, the surface and tap water samples were filtered through $0.45-\mu \mathrm{m}$ micropore membranes.

\section{Results and discussion}

\section{Optimization of enrichment procedure}

Four possible factors that may influence the enrichment efficiency, the eluent solvent and its volume, the sample volume, and the adsorbent mass were optimized. The optimization was realized following a step-by-step approach, since no SPE procedure was found for the simultaneous extraction of these pesticides using CNTs as sorbent materials. Preliminary experiments were developed using $100 \mathrm{mg}$ of MWCNTs and $100 \mathrm{~mL}$ of spiked Milli-Q water. All experiments carried out during the optimization were developed in triplicate.

\section{Determination of elution solvent and elution volume}

As pesticide absorbed on the SPE cartridge was concerned, different performances would be achieved due to the different elution power of the various solvents. Four organic solvents of different polarities including methanol $(\mathrm{MeOH})$, acetonitrile (ACN), $n$-hexane, and dichloromethane (DCM) were investigated. Figure 2 shows the efficiency of each solvent in the elution of the selected compounds. Among the four solvents tested, DCM provided the highest recovery

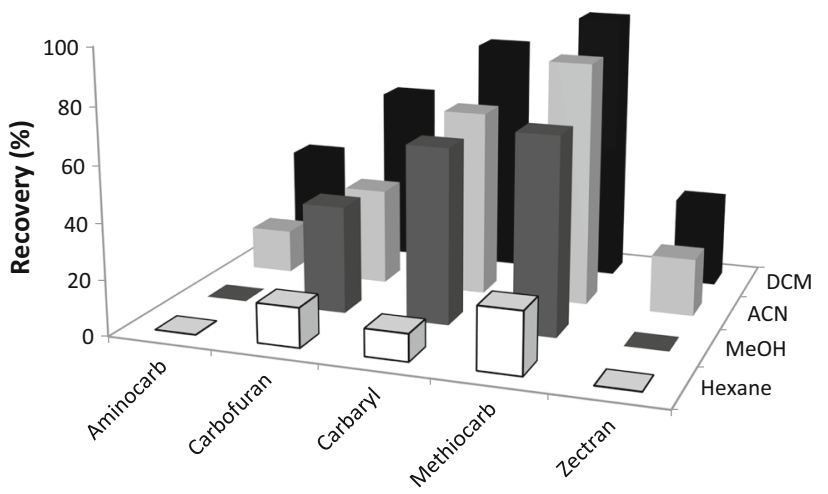

Fig. 2 Effect of different eluents. Concentration of sample solution: $5 \mu \mathrm{g} \mathrm{L}^{-1}$ of five carbamates; volume of sample: $100 \mathrm{~mL}$; eluent volume: $5 \mathrm{~mL}$; adsorbent mass: $100 \mathrm{mg}$

values, which led to better separation, and excellent symmetrical peak shape. $n$-Hexane, however, provided the lowest recovery values. As a result, DCM was chosen as the eluate in the following experiments.

The amount of eluent can also affect the enrichment efficiency. The volume of the eluent must be just sufficient to elute the compounds of interest from the sorbent. In order to evaluate the effect of the volume of eluent, a series of experiments were designed based on applying different eluent volumes of 2, 4, 5, 6, 7, 8, and $10 \mathrm{~mL}$. As shown in Fig. 3, the recoveries of five pesticides increased with increasing volumes of DCM between 2 and $7 \mathrm{~mL}$; however, the recoveries changed very little with the further increase in dichloromethane volume up to $8 \mathrm{~mL}$. Thus, in order to achieve complete elution of pesticides and save time and reagents, $8 \mathrm{~mL}$ of DCM was utilized in the following experiments.

\section{Amount of MWCNTs}

The effect of MWCNT amounts was also investigated in order to use the lowest amount as possible. For this purpose, 50, 100, 200, and $300 \mathrm{mg}$ of MWCNTs were tested. The use of 100,200 , and $300 \mathrm{mg}$ provided an efficient recovery of the analytes of interest. However, lower amounts such as $50 \mathrm{mg}$ provided lower recovery values, indicating that part of the analytes was not retained by the stationary phase (Fig. 4). However, the use of $100 \mathrm{mg}$ also provided satisfactory and similar results (mean recovery values higher than $75 \%$ for all the pesticides), and therefore, they were used in subsequent experiments in order to decrease as much as possible the amount of stationary phase used and thus reduce the cost of the SPE procedure.

\section{Sample volume}

To increase the preconcentration factor, generally, two main approaches are tried: one is the absorption ability of materials to the analytes which is the intrinsic nature that can be 
Fig. 3 Effect of eluent volume. Concentration of sample solution: $5 \mu \mathrm{g} \mathrm{L}^{-1}$ of five carbamates; elution solvent: DCM; volume of sample: $100 \mathrm{~mL}$; adsorbent mass: $100 \mathrm{mg}$

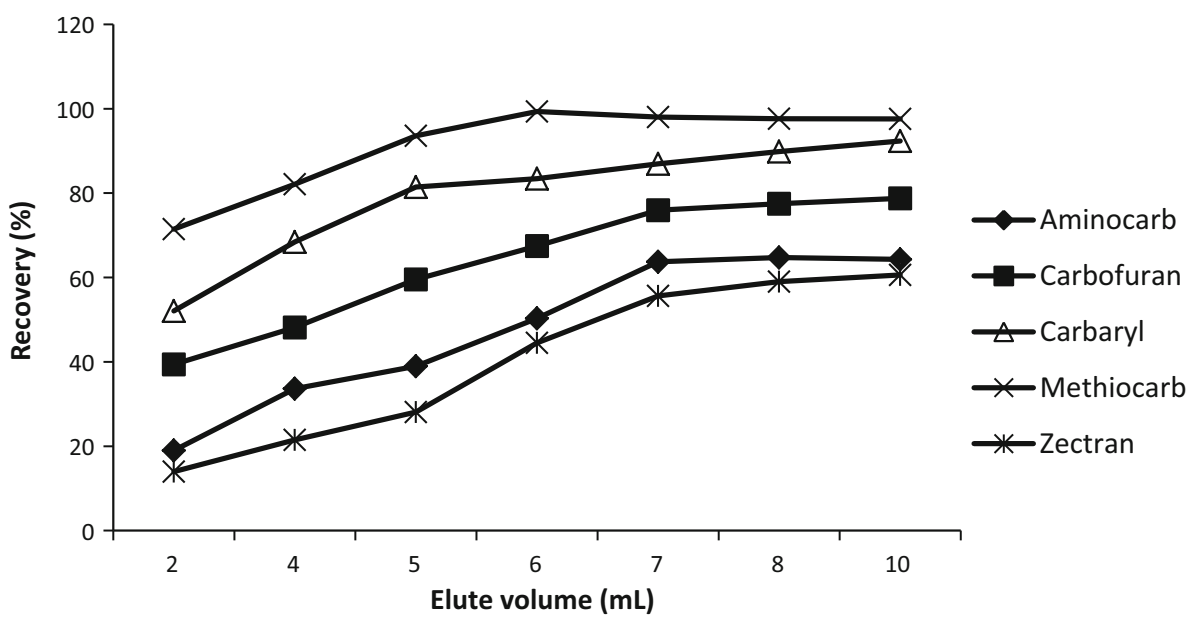

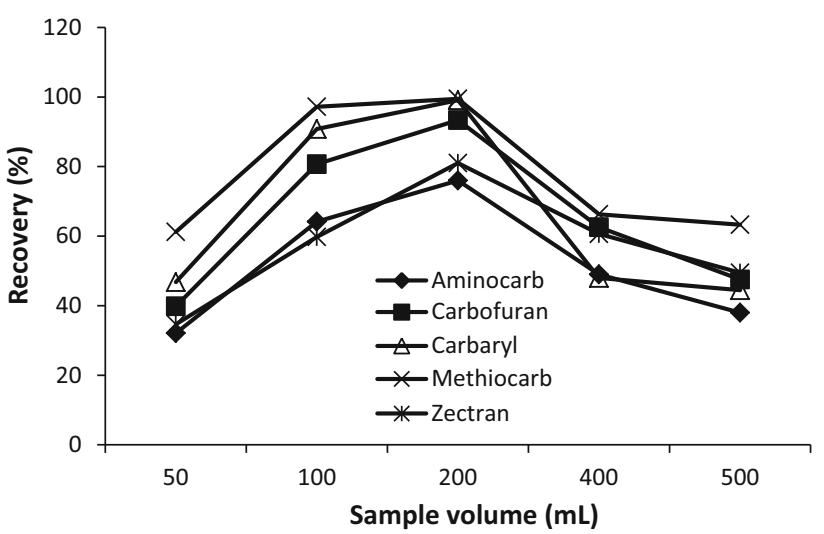

Fig. 5 Effect of sample volume. Concentration of sample solution: $5 \mu \mathrm{g} \mathrm{L}^{-1}$ of five carbamates; eluent volume: $8 \mathrm{~mL}$ of $\mathrm{DCM}$; adsorbent mass: $100 \mathrm{mg}$

\section{Cartridge reuse}

Experimental results showed that MWCNT-packed cartridge may be reused over 100 times after proper cleaning and reconditioning. However, reusing the cartridge necessitates consuming substantial amounts of expensive solvents and leads to contamination. For the highly expensive MWCNT sorbent, it may be worthy reusing the cartridge.

\section{Mechanism of sorption}

The characteristic structures and electronic properties of CNTs allow them to interact strongly with organic molecules, via non-covalent forces, such as hydrogen bonding, $\pi-\pi$ stacking, electrostatic forces, van der Waals forces, and hydrophobic interactions. These interactions as well as hollow and layered nanosized structures make them a good candidate for use as sorbents. The surface, made up of hexagonal arrays of carbon atoms in graphene sheets, interacts particularly strongly with the benzene rings of 
Table 1 Mean recoveries of five carbamates from spiked samples (RSD, $\%, n=3$ )

\begin{tabular}{|c|c|c|c|c|c|c|c|}
\hline \multirow[t]{3}{*}{ Carbamates } & \multicolumn{7}{|c|}{ Recovery (\%) } \\
\hline & \multicolumn{2}{|c|}{ Milli-Q water } & \multirow[t]{2}{*}{ Tap water } & \multirow{2}{*}{$\begin{array}{l}\text { Mellègue river } \\
\text { water }\end{array}$} & \multirow{2}{*}{$\begin{array}{l}\text { Medjerda river } \\
\text { water }\end{array}$} & \multirow{2}{*}{$\begin{array}{l}\text { Siliana river } \\
\text { water }\end{array}$} & \multirow{2}{*}{$\begin{array}{l}\text { Sidi Salem dam } \\
\text { water }\end{array}$} \\
\hline & $5 \mu \mathrm{g} \mathrm{L}^{-1}$ & $1 \mu \mathrm{g} \mathrm{L}^{-1}$ & & & & & \\
\hline Aminocarb & $103.9(2.2)$ & $99.5(2.5)$ & $101.5(2.9)$ & $100.3(5.1)$ & $99.7(4.2)$ & $99.2(2.9)$ & 94.7 (1.9) \\
\hline Carbofuran & 99.3 (1.5) & 96.7 (1.2) & 99.7 (1.8) & $98.9(3.3)$ & $97.3(1.0)$ & $96.4(2.2)$ & 99.3 (1.6) \\
\hline Carbaryl & $95.6(3.3)$ & 94.8 (1.7) & $95.1(2.5)$ & $94.8(1.3)$ & $92.0(0.9)$ & $93.2(1.5)$ & $95.2(0.9)$ \\
\hline Methiocarb & $94.3(3.7)$ & $92.2(4.9)$ & $96.4(3.0)$ & $93.3(0.4)$ & $94.2(2.5)$ & $95.8(3.5)$ & $93.9(7.0)$ \\
\hline Zectran & $101.9(4.0)$ & $99.5(2.0)$ & $100.7(0.9)$ & $99.7(2.2)$ & 99.9 (2.7) & $97.5(0.6)$ & $98.8(4.1)$ \\
\hline
\end{tabular}

carbamates. Long and Yang (2001) observed that dioxins, which have two benzene rings, were strongly adsorbed on CNTs. The sidewall of CNTs has highly hydrophobic property because of high $\pi$ electron density of $\mathrm{sp}^{2}$ carbon. Carbamates may interact with sidewall of CNTs through hydrophobic interactions. $\pi-\pi$ bonding generally takes place between bulk $\pi$ system of CNTs and carbamates with $\mathrm{C}=\mathrm{C}$ a benzene rings.

\section{Analytical performance}

The analytical parameters such as the linearity, detection limits, and reproducibility were the characteristics of the proposed method. As shown in Table 1, there were no differences in recoveries between the samples with different spiked levels. Also, the recoveries of Milli-Q water and tap water were similar. A chromatogram of five pesticides enriched with MWCNT SPE was shown in Fig. 6.

Linear ranges were achieved by determining a series of standard solutions at different concentrations. Over a 200-fold change in concentration (0.005-1 $\left.\mathrm{mg} \mathrm{L}^{-1}\right)$, calibration data could be fit a linear model for all five analytes with a typical correlation coefficient $\left(r^{2}\right)$ exceeding 0.99, as shown in Table 2, and the intercept was statically significant at $95 \%$ confidence. The detection limits of five pesticides (shown in Table 2) were obtained based on the signal as threefold of the baseline noise $(S / N=3)$ for an extraction of $200 \mathrm{~mL}$ water sample, and the LODs were in the range of 0.01-0.05 $\mu \mathrm{g} \mathrm{L}^{-1}$. The reproducibility for the extractions of $200 \mathrm{~mL}$ of spiked water samples at 5 and $1 \mu \mathrm{g} \mathrm{L}^{-1}$ concentration levels, likely to be found in environmental water, was evaluated by calculating the relative standard deviations of three replicate runs of the procedures. The results listed in Table 1 indicated that precision was satisfactory at very low concentrations with RSD in the range of 0.4-7.0\% $(n=3)$ for five pesticides. These results proved that the developed method was reliable and useful in the analysis of pesticides in water samples.

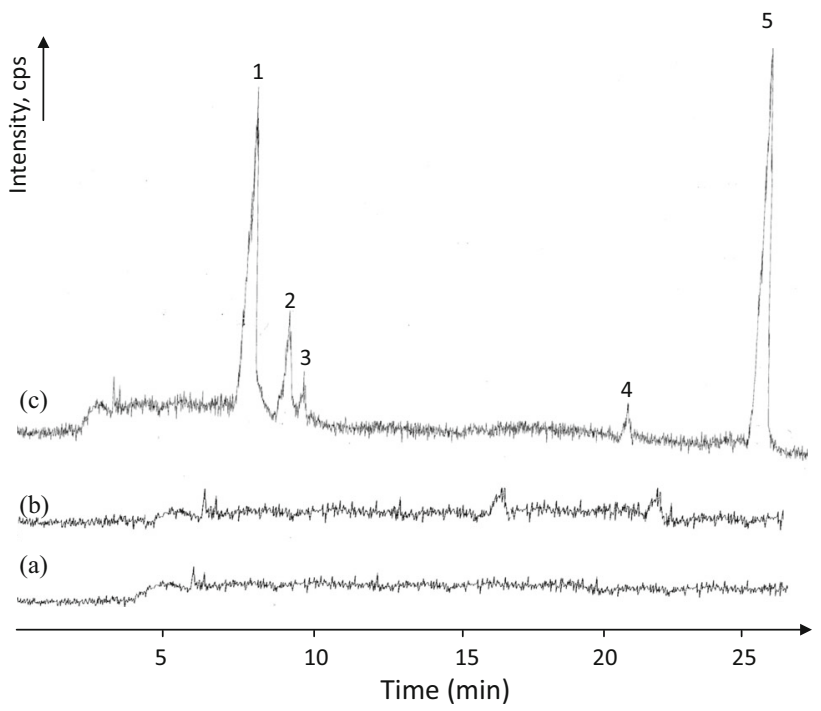

Fig. 6 Chromatograms from river water sample. Spiked concentration: $5 \mu \mathrm{g} \mathrm{L}^{-1}$ of five carbamates; eluent volume: $8 \mathrm{~mL}$ of DCM; volume of sample: $200 \mathrm{~mL}$; adsorbent mass: $100 \mathrm{mg}$. a Blank of Milli-Q water. b Non-spiked river water. c Spiked river water. The peak identifications are listed in Table 2

\section{Comparison of enrichment performance}

Comparison of enrichment performance of C18, AC, and MWCNTs was performed with Milli-Q water samples. Under the optimal conditions, the recoveries of aminocarb, carbofuran, carbaryl, methiocarb, and zectran spiked at 5 and $1 \mu \mathrm{g} \mathrm{L}^{-1}$, respectively, were obtained. The results are shown in Fig. 7. As shown in Fig. 7, these three adsorbents have different extraction capability. Obviously, MWCNTs demonstrated better enrichment performance to all studied carbamates. The results also showed that enrichment efficiency with MWCNTs was a little greater than with C18. It was probably due to the fact that $\mathrm{C} 18$ was a weak polar adsorbent compared to MWCNTS. Among the three adsorbents, AC as adsorbent gave non-ideal result according to the experiments. Adsorption of analytes was related to many factors such as particle size and properties. Regular AC used in these experiments has large size, and the blank volume 
Table 2 Calibration data of the selected carbamates

\begin{tabular}{llllll}
\hline Peak number & Carbamates & Calibration curve & $R^{2}$ & LOD $\left(\mu \mathrm{g} \mathrm{L}^{-1}\right)$ & LOQ $\left(\mu \mathrm{g} \mathrm{L}^{-1}\right)$ \\
\hline 1 & Aminocarb & $y=90318 x+24321$ & 0.996 & 0.018 & 0.09 \\
2 & Carbofuran & $y=66295 x+11024$ & 0.999 & 0.024 & 0.15 \\
3 & Carbaryl & $y=19119 x+55114$ & 0.995 & 0.015 & 0.10 \\
4 & Methiocarb & $y=10309 x+12574$ & 0.999 & 0.012 & 0.08 \\
5 & Zectran & $y=64684 x-13584$ & 0.997 & 0.044 & 0.20 \\
\hline
\end{tabular}

Fig. 7 Comparative study of enrichment efficiency between MWCNTs, AC, and C 18. Spiked concentration: 5 and $1 \mu \mathrm{g} \mathrm{L}^{-1}$ of five carbamates; eluent volume: $8 \mathrm{~mL}$ of DCM; volume of sample: $200 \mathrm{~mL}$; adsorbent mass: $100 \mathrm{mg}$

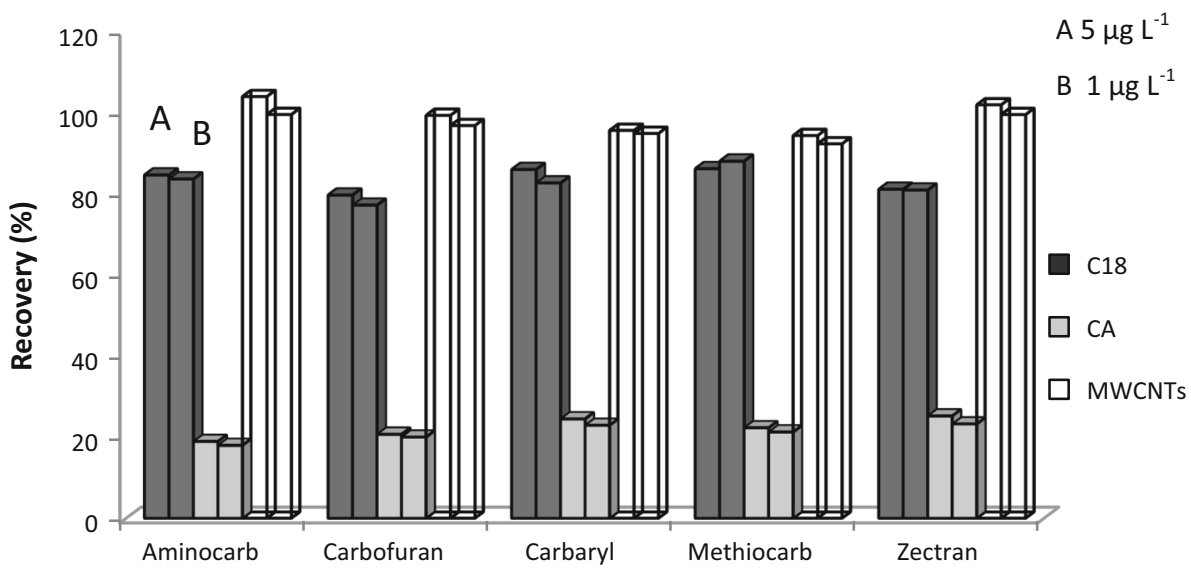

among the particles was great; therefore, the touched area and active sites were very small, and it was not surprised to get the non-expected results. From the discussion, we can see that MWCNTs can be used as packing materials for SPE in environmental analysis.

\section{Application}

In order to validate the feasibility of the method to analyze these five carbamate insecticides, the performance of the method was evaluated with five environmental water samples such as tap water, river water, and dam water. First, under the optimal experimental conditions, a blank of the five environmental waters was run to verify whether the target compounds were or were not present. It was found that there were no peaks at the related peak locations and that aminocarb, carbofuran, carbaryl, methiocarb, and zectran were not found in the samples. The measured spiked recoveries are shown in Table 1 , and it was found that the recoveries of five pesticides were acceptable in the range of 92.2-103.9\% with the RSD below $11 \%$. The recoveries shown in Table 1 indicate that the matrix effects between Milli-Q water, tap water, river water, and dam water were slight. The chromatograms of the blank and spiked solutions are shown in Fig. 6. The quantification limit (LOQ) was determined as being the signal at least 10 times greater than the noise signal. Quantification limits were between 0.08 and $0.2 \mu \mathrm{g} \mathrm{L}^{-1}$ (Table 2).

\section{Conclusion}

In the present work, a fast, sensitive method for the analysis of aminocarb, carbofuran, carbaryl, methiocarb, and zectran in environmental water samples was established. MWCNTs, a new nanoscale material, showed excellent adsorption properties as SPE adsorbents. More important, the main advantage of the SPE procedure proposed here is that it allows the simultaneous extraction of selected carbamate insecticides from environmental water without any complicated pretreatment of the sample. The comparison of MWCNTs with C 18 and $\mathrm{AC}$ for SPE indicated that $\mathrm{AC}$ gave a non-ideal result, and MWCNTs had much better extraction capacity. The proposed method could be utilized for regular monitoring of these compounds in environmental water samples, and it will have a large potential to be widely used for the determination of other different carbamate insecticides.

Acknowledgments The authors would like to express their gratitude to the ministry of agriculture for providing the water samples.

\section{References}

Albero B, Brunete CS, Tadeo JL (2005) Multiresidue determination of pesticides in juice by solid-phase extraction and gas chromatography-mass spectrometry. Talanta 66:917-924

Caballero-Díaz E, Valcárcel M (2014) Carbon nanotubes as SPE sorbents for the extraction of salicylic acid from river water. J Sep Sci 37:434-439 
Cai YQ, Jiang GB, Liu JF, Zhou QX (2003) Multi-walled carbon nanotubes packed cartridge for the solid-phase extraction of several phthalate esters from water samples and their determination by high performance liquid chromatography. Anal Chim Acta 494:149-156

Chen GC, Shan XQ, Pei ZG, Wang HH, Zheng LR, Zhang J (2011) Adsorption of diuron and dichlobenil on multiwalled carbon nanotubes as affected by lead. J Hazard Mater 188:156-163

Crecente RMP, Lovera CG, García JB, Méndez JÁ, Martín SG, Latorre CH (2014) Multiwalled carbon nanotubes as a sorbent material for the solid phase extraction of lead from urine and subsequent determination by electrothermal atomic absorption spectrometry. Spectrochim Acta B 101:15-20

D'Archivio AA, Fanelli M, Mazzeo P, Ruggieri F (2007) Comparison of different sorbents for multiresidue solid-phase extraction of 16 pesticides from groundwater coupled with high-performance liquid chromatography. Talanta 71:25-30

De Martino A, Iorio M, Xing BS, Capasso R (2012) Removal of 4-chloro-2 methylphenoxyacetic acid from water by sorption on carbon nanotubes and metal oxide nanoparticles. RSC Adv 2:5693-5700

Deng J, Shao YS, Gao NY, Deng Y, Tan CQ, Zhou SQ (2012) Multiwalled carbon nanotubes as adsorbents for removal of herbicide diuron from aqueous solution. Chem Eng J 193:339-347

El Atrache LL, Sabbah S (2003) Determination of phenyl- $N$-methylcarbamates and their hydrolysis products in water, using solidphase extraction and reversed-phase liquid chromatography with UV and electrospray mass spectrometric detection. Can J Chem 81:971-981

El-Sheikh AH, Sweileh JA, Al-Degs YS, Insisi AA, Al-Rabady N (2008) Critical evaluation and comparison of enrichment efficiency of multi-walled carbon nanotubes, C18 silica and activated carbon toward some pesticides from environmental waters. Talanta 74:1675-1680

EU Council (1998) Directive on the quality of water intended for human consumption, 98/83/CE. European Union, Brussels

Gupta VK, Saleh TA (2013) Sorption of pollutants by porous carbon, carbon nanotubes and fullerene-an overview. Environ Sci Pollut Res 20:2828-2843

Gupta VK, Agarwal S, Saleh TA (2011a) Synthesis and characterization of alumina-coated carbon nanotubes and their application for lead removal. J Hazard Mater 185:17-23

Gupta VK, Agarwal S, Saleh TA (2011b) Chromium removal by combining the magnetic properties of iron oxide with adsorption properties of carbon nanotubes. Water Res 45:2207-2212

Gupta VK, Kumar R, Nayak A, Saleh TA, Barakat MA (2013) Adsorptive removal of dyes from aqueous solution onto carbon nanotubes: a review. Adv Colloid Interface Sci 193-194:24-34

Iijiama S (1991) Helical microbubules of graphitic carbon. Nature 354:56-58

Iijiama S, Ichihashi T (1993) Single-shell carbon nanotubes of 1-nm diameter. Nature 363:603-605

Jun-ping X, Qing-xiang Z, Hua-hua B (2007) Application of multiwalled carbon nanotubes treated by potassium permanganate for determination of trace cadmium prior to flame atomic absorption spectrometry. J Environ Sci 19:1266-1271

Krutz LJ, Senseman SA, Sciumbato ASJ (2003) Solid-phase microextraction for herbicide determination in environmental samples. J Chromatogr A 999:103-121

Lancas FM (2004) Extração em fase sólida. Editora Rima, São Carlos

Latorre C, Mendez A, Garcia JB, Garcia Martin S, Peña Crecente RM (2012) Carbon nanotubes as solid-phase extraction sorbents prior to atomic spectrometric determination of metal species: a review. Anal Chim Acta 749:16-35

Long RQ, Yang RT (2001) Carbon nanotubes as superior sorbent for dioxin removal. J Am Chem Soc 123:2058-2059

Picó YF, Ruiz MMJ, Font GJ (2007) Current trends in solid-phasebased extraction techniques for the determination of pesticides in food and environment. Biochem Biophys Methods 70:117-131
Rambabu N, Guzman CA, Soltan J, Himabindu V (2012) Adsorption characteristics of atrazine on granulated activated carbon and carbon nanotubes. Chem Eng Technol 35:272-280

Ramos MA, Borges JH, Pérez LMR, Rodríguez-Delgado MA (2008) Simultaneous determination of seven pesticides in waters using multi-walled carbon nanotube SPE and NACE. Electrophoresis 29:4412-4421

Salam MA (2013) Removal of heavy metal ions from aqueous solutions with multi-walled carbon nanotubes: kinetic and thermodynamic studies. J Environ Sci Technol 10:677-688

Saleh TA (2011) The influence of treatment temperature on the acidity of MWCNT oxidized by $\mathrm{HNO} 3$ or a mixture of HNO3/ H2SO4. Appl Surf Sci 257:7746-7751

Saleh TA, Gupta VK (2012) Photo-catalyzed degradation of hazardous dye methyl orange by use of a composite catalyst consisting of multi-walled carbon nanotubes and titanium dioxide. J Colloid Interface Sci 371:101-106

Saleh TA, Gupta VK (2014) Processing methods, characteristics and adsorption behavior of tire derived carbons: a review. Adv Colloid Interface Sci 211:93-101

Saleh TA, Agarwal S, Gupta VK (2011) Synthesis of MWCNT/MnO2 and their application for simultaneous oxidation of arsenite and sorption of arsenate. Appl Catal B 106:46-53

Sanusi A, Guilet V, Montury M (2004) Advanced method using microwaves and solid-phase microextraction coupled with gas chromatography-mass spectrometry for the determination of pyrethroid residues in strawberries. J Chromatogr A 1046:35-40

Song XY, Shi YP (2013) Carbon nanotubes-reinforced hollow fiber solid-phase microextraction coupled with high performance liquid chromatography for the determination of carbamate pesticides in apples. Chen Food Chem 139:246-252

Soriano JM, Jiménez B, Font G, Moltó JC (2001) Analysis of carbamates pesticides and their metabolites in water by solid phase extraction and liquid chromatography: a review. Crit Rev Anal Chem 31:19-52

Tsoukali H, Tsoungas M (1996) Fatal human poisonings in northern Greece. Vet Hum Toxicol 38:366-367

U.S. E.P.A. (1985) Method 531 EPA-600/4-85/054. United States Environmental Protection Agency, Washington

U.S. E.P.A. (1992) National Survey of Pesticides in Drinking Water Wells, Phase II Report, EPA 570/9-91-020

Worek F, Aurbek N, Wetherell J, Pearce P, Mann T, Thiermann H (2008) Inhibition, reactivation and aging kinetics of highly toxic organophosphorus compounds: pig versus minipig acetylcholinesterase. Toxicology 244:35-41

Zhao G, Wang C, Wu Q, Wang Z (2011) Determination of carbamate pesticides in water and fruit samples using carbon nanotube reinforced hollow fiber liquid-phase microextraction followed by high performance liquid chromatography. Analytical Methods 3:1410-1417

Zhou QX, Wang WD, Xiao JP, Wang JH, Liu GG, Shi QZ, Guo GL (2006) Preconcentration and determination of nicosulfuron, thifensulfuron-methyl and metsulfuron-methyl in water samples using carbon nanotubes packed cartridge in combination with high performance liquid chromatography. Microchim Acta 152:215-224

Zhoua Q, Xiao J, Wang W (2006a) Using multi-walled carbon nanotubes as solid phase extraction adsorbents to determine dichlorodiphenyltrichloroethane and its metabolites at trace level in water samples by high performance liquid chromatography with UV detection. J Chromatogr A 1125:152-158

Zhoua Q, Xiao J, Wang W, Liu G, Shi Q, Wang J (2006b) Determination of atrazine and simazine in environmental water samples using multiwalled carbon nanotubes as the adsorbents for preconcentration prior to high performance liquid chromatography with diode array detector. Talanta 68:1309-1315 